\title{
Teaching and Assessing Engineering Design: A Review of the Research
}

\author{
Susan Campbell \\ Carol L. Colbeck \\ The Pennsylvania State University
}

According to the National Academy of Sciences (1995), undergraduate engineering education in the United States currently focuses on the study of engineering science at the expense of design. In a brief history of engineering design education, Eder (1991) explains that in the 1950s the engineering curricula shifted from a focus on teaching students about technology used in industry to an emphasis on engineering science including math, physics, and chemistry. He contends that faculty began to become more research-oriented and institutions of higher education placed less value on industry experience among faculty at roughly the same time. Eder argues that these factors contributed to the recent lack of emphasis on design skills and abilities in engineering curricula. He attributes renewed attention to design in curricula to a 1985 National Science Foundation initiative that resulted in funding to improve undergraduate engineering design education.

The Accreditation Board for Engineering Technology (ABET) and many industry representatives join the National Academy of Sciences in calling for a renewed emphasis on the development of design skills among undergraduate engineering students. ABET stipulates that graduates of accredited engineering programs demonstrate skills and competencies such as an "ability to design a system, component, or process; an ability to function on multidisciplinary teams; an ability to identify, formulate, and solve engineering problems;... [and] an ability to communicate effectively" (ASEE Prism, 1997, p. 41). Likewise, industry representatives emphasize that undergraduate engineering students should develop an understanding of the design process as well as the ability to work in teams, communicate effectively, think critically, and solve problems (Rhoads, et al., 1995; Coleman, 1996).

This paper begins with a definition of engineering design followed by a summary of the research on teaching design and assessing student design competence and concludes with implications for future research to improve engineering education.

\section{Definition of engineering design}

Engineering design is complex problem solving (Lewis \& Samuel, 1989) that involves generating and evaluating specifications to achieve objectives and satisfy constraints (Dym, 1994). This definition implies that: (1) engineering design is a cognitive process that can be modeled and understood; (2) representations exist for both the form and function of the processes involved in design; (3) the objectives of the design problem and any constraints can be determined from this representation; (4) design alternatives can be generated using problemsolving techniques; (5) fabrication specifications can be determined from the designs; and (6) designs can be assessed and evaluated at various points in the design process (Dym, 1994). 


\section{What students should learn from design}

The methods faculty choose to teach engineering design relate to the skills and competencies they wish to develop in students. For instance, faculty often choose to use design projects because these projects involve open-ended problems that more closely resemble the work of professional engineers (Harris \& Jacobs, 1995). Open-endedness is useful because students learn that at times no one "right answer" to a problem exists. Engineering design education often involves competition. Some individuals believe that this approach simulates the marketplace environment of professional engineering practice as well as generating student enthusiasm for the design project (Harris \& Jacobs, 1995). Others think that it reinforces the idea that design is open-ended or that multiple approaches to the client's objectives can be achieved (Dym, 1994).

Creativity has become an issue of primary concern in engineering because of increased competitiveness in developing new designs. Clapham and Schuster (1992) implemented a creativity training program and tested whether it was effective in increasing the creativity of engineering students. The experimental group participated in a one-hour creativity training session that included a discussion of idea-generating techniques. The control group, on the other hand, was involved in an interview skills training session. Results of the analysis of creativity test scores indicate that the creativity training has a significant effect on creativity gain scores. This study suggests that creativity training should be included in design education if creativity is one of the learning objectives.

ABET mandates that graduates of engineering programs must demonstrate ability to solve engineering problems which require critical thinking skills (ASEE Prism, 1997). Sanchez, Hight, and Gainen (1995) describe their attempts to improve the critical thinking skills of engineering students in several sections of an introductory engineering graphics course. The teaching methods faculty used included a discussion of the design process, an emphasis on sketching and visualization techniques, an opportunity to be involved in a brainstorming exercise, a critical discussion of former students' posters, developing criteria for evaluating their own posters, and creating and presenting posters about their designs. The authors provide minimal information about how they judged student improvement in critical thinking except that they based their observations on the posters students produced and looked for improvement using Perry's scheme of intellectual development. In future courses, the faculty plan to use an instrument to assess students' development on the Perry scheme and require students to provide more documentation of the design process through methods such as journals.

ABET stresses that engineering graduates should demonstrate an ability to communicate effectively (ASEE Prism, 1997). Design projects typically involve written and oral reporting on the project (Harris \& Jacobs, 1995). These writing assignments exist not only to contribute to the development of communication skills, but also to simulate industry practice. Design projects also often involve teamwork. This teamwork helps students to improve their communications skills. The National Academy of Sciences (1995) asserts that graduates of engineering programs must be prepared to work in a global economy. Teamwork highlights the fact that individuals approach learning from multiple perspectives and that students have much to learn from their peers (Dally \& Zhang, 1993). Similarly, Byrd and Hudgins (1995) assert that "the team approach 
provides an inclusive learning environment for traditionally excluded groups such as minority students and women" (p. 35). This approach assumes that requiring students to work together on a team not only exposes them to differing viewpoints, but also makes students more accepting of those viewpoints. Design projects might also prepare students for work in a global economy by adding context to the content of engineering design. This context includes the economic, environmental, ethical, historical, and social issues that are involved in design.

Reflection is a skill that has recently received attention. According to Gorman, Richards, Scherer, and Kagiwada (1995), reflection is important particularly for first-year students or inexperienced designers. Reflection provides these students with the opportunity to contemplate problem-solving strategies and problem representations and to develop new ways of reaching a solution that might be apparent to more experienced students. Students can reflect on the design process in diaries, journals, or notebooks.

\section{$\underline{\text { How faculty teach design }}$}

Engineering faculty tend to use at least one of four approaches to teaching design: lecture, faculty as guide or coach, case study, and industry involvement. The lecture method is a traditional style of instruction in which students are asked to read materials before class and the faculty member expounds upon those readings during class. Dym (1994) argues that these methods should initiate discussions about definitions of design and the design process including both inductive and deductive approaches. Eder (1994) explains that engineering design is rarely done by an individual working alone. Therefore, faculty who teach engineering design should include instruction on teamwork and group dynamics. Finally, Harris and Jacobs (1995) maintain that lectures should also address the topic of effective oral presentation techniques.

Some scholars believe that faculty should serve as guides or consultants in engineering design education. In contrast to the lecture method, this approach emphasizes faculty/student interaction. For instance, Dym (1994) encourages "interactive dialog" between the instructor(s) and students so that students learn that a seemingly simple statement such as "a safe ladder" involves not only clarifying objectives, but interacting with individuals who hold various viewpoints, and developing design specifications that can be calculated. Similarly, Dally and Zhang (1993) emphasize that the teaching and learning process involves two-way communication between the student and faculty member. They describe the role of the faculty member as consultant and coach, providing assistance and encouragement. At times, instructors might also act as supervisors and customers for the design (Harris \& Jacobs, 1995). In other words, the instructor gives advice regarding specific design concerns, but not guidance regarding general design issues.

Some faculty find that requiring students to write case studies of their engineering design activity is a more effective teaching technique than a paper. For example, Smith (1991) compares the merits of using cases versus papers in engineering design education. He defines an engineering case as a written account of an actual engineering activity that contains detailed information such as drawings, test data, and budget information, and often involves non-technical information. The case study includes report descriptions of unsuccessful attempts at reaching a solution. In 
contrast, an engineering paper focuses on presenting results and often supports a single, particular solution. As a result, a paper explicates little of the design practice that took place. Smith reports that a survey of students who learned design using cases revealed that "they believe cases helped them: discriminate between fact and opinion, search for more alternative solutions, identify and define practical problems, spot key facts amid less relevant data, tolerate ideas and errors of others, appreciate what engineers do and what technical facts they use, and understand the criteria for evaluating design and for judging engineering procedures" (p. 269). Thus, students believe case studies are more useful methods than engineering papers in teaching the design process.

The literature on undergraduate engineering design education also suggests involving industry representatives. For example, Knox and associates (1995) report that industry representatives who serve as co-instructors of a course taught at the University of Oklahoma provide additional opportunities for students to be exposed to "both the demands placed on and the rewards realized by practicing professional engineers" (p. 9). This exposure occurs through interactions with the industry representative, site visits, and on-site presentations. An industry representative may also serve in a more informal role such as a liaison (Dym, 1994).

\section{How faculty assess design competence}

Currently, if the issue of assessing student design competence is discussed at all, it is embedded in articles on the teaching of engineering design. These articles revealed several forms of assessment: faculty, industry representative and peer evaluation of design projects, standardized tests of domain knowledge, surveys of students or employers, and job/graduate school placement.

One commonly used method of assessing the quality of engineering designs involves "design juries" (Dym, 1994). These design juries consist of practicing engineers and engineering faculty who observe design team presentations and evaluate the quality of the design projects based on the design objectives. At West Virginia University, this method is referred to as "the Majors" which are design projects that students complete individually and defend in the presence of two faculty members. If the faculty find weaknesses in the student's defense, they might recommend remedial work or other methods for improvement. According to Shaeiwitz, one drawback of the Majors method is that it is faculty time intensive which may prevent many faculty from using this approach. Miller and Olds (1994) use a method much like the design jury method in evaluating student engineering design. The senior design course they teach requires students to work in multidisciplinary design teams to solve real-world problems. Students must also work with industrial or government clients. Each client evaluates the performance of their student design team in the areas of technical quality, problem-solving ability, communications quality, and team performance.

Peer evaluation is another method of assessing design frequently used in engineering courses. This method requires students to evaluate the performance of fellow team members in completing the design project. For example, Byrd and Hudgins (1995) describe the individual peer evaluation they use in teaching a senior design course for electrical and computer engineering students. Using a scale of 0-100, students rate themselves as well as their teammates 
in several areas such as whether the individual completed their assigned part of the project, how well that individual cooperated with other team members, if the student was available for meetings, and if the individual demonstrated creativity. Team leaders are also evaluated on a separate scale. In this class, the individual peer evaluation scores account for 10 percent of the final course grade. Performance of the vehicle in the track competition and team performance (as judged by the faculty) in areas such as meeting deadlines each accounted for 40 percent of the grade. The remaining 10 percent of the grade is based on a mid-term demonstration.

Standardized tests are also used assess content knowledge of engineering design. Shaeiwitz (1996) explains that engineering in the University of Tennessee system uses a standardized test, the Fundamentals of Engineering (FE) Examination, to measure outcomes. He adds that the Graduate Record Examination (GRE) subject test could also be used. Some institutions administer these tests to students upon entrance as well as at graduation in a "value added" approach to assessment.

Another method of assessment Shaeiwitz mention involves questionnaires sent to graduates and possibly employers to assess the graduate's preparation for their job from both the graduate's and employer's perspectives. Miller and Olds (1994) describe a method that involves surveying students about the engineering design process. Faculty survey students at the beginning and end of a course and look for changes in students' perceptions while they are in the course. Also, they survey seniors who complete traditional, discipline-specific design courses and compare their perceptions with those of senior who take a design course that requires students to work in multidisciplinary teams. This survey includes questions on both technical (such as design strategies) and non-technical (such as communication skills) areas.

Finally, Shaeiwitz (1996) describes a method of assessment that examines the design process rather than the product. At West Virginia University, diaries or journals are used to gather information that is typically omitted in reports such as alternatives that were considered or deadends that were encountered.

\section{Conclusion}

A review of the literature revealed no articles specifically about how to assess students' designs. The literatures on engineering design itself and how to teach design are relatively new. Studies of the engineering design process began to appear in the literature approximately 10 years ago. Recently, scholars started to describe the methods used to teach engineering design; however, as mentioned earlier those articles often do not involve empirical investigations. Articles addressing the methods used to teach and assess engineering design tend to describe current practice rather than explore research questions. Students who engage in design projects should learn how to solve open-ended problems, creativity, critical thinking, teamwork, and reflective practice. Methods for teaching design lecture, coaching students through projects, case studies, and work with industry representatives include projects, teamwork, presentations, competition, and lectures on the design process as well as group dynamics, presentation techniques, and issues such as ethics. Assessment of student design competence involves methods such as juries or panels of experienced designers, peer evaluations, and journals. 
Several conclusions can be drawn based on the research. First, future research should focus on how teamwork and the design process affect design competence. Next, faculty should use multiple methods of assessing student design competence to determine students' performance during the project as well as the quality of the product. Finally, although faculty often require students to work in teams on design projects, they fail to provide instruction on group dynamics. Thus, faculty should consider including instruction on teamwork to promote student learning of engineering design.

References

Accreditation Board for Engineering and Technology. (March 1997). Engineering criteria 2000: Criteria for accrediting programs in engineering in the United States. ASEE Prism, 41-42.

Byrd, J. S., \& Hudgins, J. L. (1995). Teaming in the design laboratory. Journal of Engineering Education, 84(4), 335-341. 24-31.

Coleman, R. J. (September 1996). The engineering education coalitions: A progress report. ASEE Prism,

Dally, J. W., \& Zhang, G. M. (1993). A freshman engineering design course. Journal of Engineering Education, 82(2), 83-91.

Dym, C. L. (1994). Teaching design to freshman: Style and content. Journal of Engineering Education, 83(4), 303-310.

Eder, W. E. (1991). Engineering design education: Situation report. Design Studies, 12(4), 261-267.

Gorman, M. E., Richards, L. G., Scherer, W. T., \& Kagiwada, J. K. (1995). Teaching invention and design: Multi-disciplinary learning modules. Journal of Engineering Education, 84(2), 175-185.

Harris, T. A., \& Jacobs, H. R. (1995). On effective methods to teach mechanical design. Journal of Engineering Education, 84(4), 343-349.

Knox, R. C., Sabatini, D. A., Sack, R. L., Haskins, R. D., Roach, L. W., \& Fairbairn, S. W. (1995). A practitioner-educator partnership for teaching engineering design. Journal of Engineering Education, 84(1), 5-11.

Miller, R. L., \& Olds, B. M. (1994). A model curriculum for a capstone course in multidisciplinary engineering design. Journal of Engineering Education, 83(4), 311-316.

National Academy of Sciences, Commission on Engineering and Technical Systems. (1995). Engineering education: Designing an adaptive system. Washington, DC: National Research Council.

Rhoads, R., Paulson, K., Campbell, S., \& Fairweather, J. (1995). Final evaluation report: Engineering coalition of schools for excellence in education and leadership technology reinvestment project. University Park, PA: The Pennsylvania State University, Center for the Study of Higher Education.

Sanchez, L. A., Hight, T. K., \& Gainen, J. (1995). Critical thinking and design: Evolution of a freshman engineering graphics course. In Gainen, J., \& Willemsen, E. W. (Eds.), Fostering student success in quantitative gateway courses. New Directions for Teaching and Learning, No. 61, 67-76. San Francisco: Jossey-Bass Publishers.

Shaeiwitz, J. A. (1996). Outcomes assessment in engineering education. Journal of Engineering Education, 85(3), 239-246.

Smith, C. O. (1991). Cases versus papers in design education. Design Studies, 12(4), 268-271.

SUSAN CAMPBELL is a doctoral student in Higher Education at Pennsylvania State University. Currently, she serves as a graduate research assistant in the Center for the Study of Higher Education. Her primary research interests are in the areas of teaching and learning as well as comparative and international issues in higher education. Susan is an active member of the American Educational Research Association and the Association for the Study of Higher Education. 
CAROL COLBECK is assistant professor and research associate at the Center for the Study of Higher Education at The Pennsylvania State University. She is associate director of evaluation for the NSF-funded Engineering Coalition of Schools for Excellence in Education and Leadership (ECSEL) grant. Dr. Colbeck directs a three year Field-Initiated Study, "Enhancing Faculty Contributions to Learning Productivity," funded by the U.S. Department of Education. She has conducted research on faculty work behavior, decision making in academic departments and curricular reform. 